\title{
AFRESCO SICILIANO OU DA BELEZA AVISTADA: ENSAIO DE FILOLOGIA CAMILLERIANA
}

\section{SICILIAN FRESCO OR ON THE GLIMPSED BEAUTY: ESSAY OF CAMILLERIAN PHILOLOGY}

\author{
Giuseppe Marci* Rafael Ferreira da Silva**

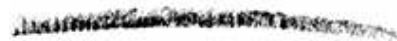 \\ RESUMO
}

A Sicília, região insular no sul da Itália, no meio do mar Mediterrâneo, apresenta uma história geológica e humana única e perceptível, o que proporciona a seus filhos uma forte noção de pertença. Não somente àqueles que sempre estiveram ali, mas também aos que migraram para outras cidades italianas ou para outros países. Neste artigo, buscou-se traçar paralelos entre os pontos de vista da narrativa do escritor sículo-americano Jerre Mangione em "Reunião na Sicília" (1950), traduzido para o italiano em 1992, e a do conta-histórias siciliano Andrea Camilleri em "Excursão a Tíndari" (2000) e em "A Beleza Avistada" (2017), ao recontarem um mesmo acontecimento vivenciado na ilha, nos anos 1940, por ambos quando jovens. São levadas em consideração questões relacionadas à identidade cultural siciliana dos escritores: Mangione, como filho de imigrantes, nascido e criado nos Estados Unidos, e Camilleri, nascido e criado na ilha italiana, radicado em Roma até o seu falecimento em 2019.

Palavras-chave: Identidade Cultural Siciliana. Andrea Camilleri. Jerre Mangione.

\section{ABSTRACT}

Sicily, an island region in southern Italy, in the middle of the Mediterranean Sea, has a unique and perceptible geological and human history, which gives its people a strong sense of belonging. Not only to those who have always been there, but also to those who have migrated to other Italian cities or to other countries. In this work, we sought to draw parallels between the points of view of the narrative of the Sicilian-American writer Jerre Mangione in "Reunion in Sicily" (1950), translated into Italian in 1992, and that of the Sicilian storyteller Andrea Camilleri in "Excursion to Tíndari" (2000) and "The Glimpsed Beauty" (2017), when they tell the same event experienced in Sicily, in the 1940s, by both when they were young. Issues related to the Sicilian cultural identity of the writers are taken into account: Mangione, as son of Sicilian immigrants, born and raised in the United States, and Camilleri, while born and raised on the Italian island, based in Rome until his death in 2019.

Keywords: Sicilian Cultural Identity. Andrea Camilleri. Jerre Mangione.

*Professor Doutor aposentado do ex-Depto de Filologia, Literatura e Linguística da Università degli Studi di Cagliari. Diretor da Revista Quaderni Camilleriani e do Site Camillerindex (https://www.camillerindex.it). E-mail: campusmarci@gmail.com. Orcid: 0000-0003-2215-6543

**Professor Doutor do Depto de Letras Estrangeiras da UFC. Atua no programa de Pós-Graduação em Estudos da Tradução - POET (UFC). Membro do Comitê Científico da Revista Quaderni Camilleriani. Bolsista CAPES de Estágio Sênior na Università degli Studi di Cagliari (mar/20 a fev/21). E-mail: rafael.ferreira@letras.ufc.br. Tradutor do artigo. Orcid: 0000-0001-7819-937X. 


\section{Ao céu de Agrigento}

cujo azul é de uma intensidade que de tirar o fôlego

Foi uma motivação muito original que nos fez desembarcar na costa da Sicília, para chegar até aqui, em Agrigento e em Porto Empedocle, respectivamente as fictícias Montelusa e Vigàta das obras de Andrea Camilleri.1

Foram os ventos dos seus 2400 anos de história que inflaram as velas da nossa jangada de estudos camillerianos, pacientemente construída na vizinha ilha da Sardenha, nesse um quarto de século.

Nos últimos anos percorremos o Mediterrâneo, alcançando as margens europeias, as da Ásia, na terra do Líbano; e chegamos na América: no México, no Brasil, onde os estudos camillerianos crescem pela semente plantada em Fortaleza pelo professor Rafael Ferreira da Silva.

Mas, mesmo com o orgulho dos feitos e com a gratidão a todos que permitiram que os resultados fossem alcançados, devo dizer que eu e os amigos, com os quais - todos juntos chegamos a uma significativa meta, não estávamos satisfeitos: sentíamos que havia um destino a alcançar, não por razões sentimentais, mas por uma exigência lógica - a Sicília.

Apresentando um livro seu traduzido em italiano nos últimos meses de 2019, John Sutherland propôs um conceito que convém ressaltar:

"Não há um lugar ali", escreveu desdenhosa Gertrude Stein, parisiense por escolha, falando de Oakland, a sua cidade natal. Palavras desse tipo não fazem sentido em nenhum dos livros utilizados nesta obra. Aludindo à falta de história da cidade californiana, representando a localidade como anônima, decepcionante, sem nenhum sinal distintivo ou detalhe digno de memória. Com esta frase, Stein sintetiza acintosamente a indefinição da "noção de pertença", daquele "existir" fundamental, sem o qual os limites de uma cidade desaparecem2.

No nosso caso, por outro lado, não vamos lidar com uma cidade sem história, com uma noção de pertença indefinida, mas com uma terra cuja história geológica e humana é claramente visível, até aos olhos do turista mais distraído.

Além disso: a noção de pertença, patrimônio inalienável de qualquer indivíduo nascido na Sicília, foi também destilado e exposto nas páginas de escritores ilustríssimos: Verga, De Roberto, Pirandello, Brancati, Tomasi di Lampedusa, Sciascia, Bufalino, Consolo e Camilleri, para listar uma primeira seleção que pode ser bem ampliada, se se incluem autores menos conhecidos, inclusive os não nascidos na Sicília, mas do outro lado do Oceano: sicilianos emigrantes. Todos capazes de expressar, e óbvio que profundas diferenças, a tal noção de pertença que os une e que eles souberam, a partir da dimensão local, transformá-la no elemento propulsor de um valor literário universalmente reconhecido.

A reflexão que quero propor se articula com três textos publicados na Itália em 1992, 2000 e 2017. Os últimos dois pertencem a Andrea Camilleri, que narrou um mesmo episódio fazendo dele elemento do romance Excursão a Tíndari3 e da escrita memorial intitulada, de fato, Esercizi di memoria (2017)[Exercícios de memória]4.

Porém, do mesmo episódio tem rastros em algumas páginas de Riunione in Sicilia [Reunião na Sicília], "uma espécie de diário"s, como o definiu Giuseppe Prezzolini, publicado em Palermo, em 1950, pelo autor estadunidense Jerre Mangione, dedicado a Andrea Camilleri e Dante Bernini, traduzido depois em italiano por Maria Anita Stefanelli e publicado pela Sellerio em 1992.

Vale dizer quem são Jerre Mangione e Dante Bernini e por que encontramos os seus nome ligados ao de Camilleri.

Gerlando Mangione (o próprio nome - que é o de San Gerlando, primeiro bispo de Agrigento, a partir de 1088, depois da ocupação muçulmana - já conduz a um destino) nasceu em Rochester, no estado de Nova Iorque, em 1909, de pais originários da província de Agrigento, 
emigrados para os Estados Unidos no fim do século XIX; ali cresceu e estudou, amadurecendo para uma sólida consciência de cidadão estadunidense. Em 1936, realizou a primeira viagem para a Sicília, o que the causou uma impressão deprimente, e depois, sobretudo por razões familiares, após ganhar uma bolsa de estudo Guggenheim, retornou em 1947. Reunião na Sicília conta esta experiência e, ao lê-lo com atenção, desmente o título do artigo (todavia perspicaz, no conteúdo) Os emigrantes retornam para a Itália e não se reconhecem ali6[Gli emigrati ritornano in Italia e non ci si ritrovano più.], de Giuseppe Prezzolini, que o editor Sellerio traz à tona na conclusão do livro. Mangione está no auge da maturidade, é um homem inteligente, sólido pela formação recebida, o que marca a sua identidade. Contemporaneamente, tem uma modulação desta identidade pessoal que reforça a motivação para compreender e se sintonizar com o espírito do lugar: "eu tinha a Sicília no sangue"7.

Quando chega pela segunda vez à ilha tem, portanto, uma dupla visão de mundo. Esse tipo de sensação pode assustar os medrosos, mas fortalece os que fazem disso uma motivação, extraindo dali múltiplas chaves de leitura. Mangione vê e descreve a Sicília sem clemência, mas com capacidade de se sintonizar. Não é um emigrado que retorna e não se reconhece, mas um americano culto e sensível que vê, compreende e participa. Surpreende e sofre, às vezes, pelo magma humano, político e social em plena efervescência, depois de vinte anos de fascismo, do desembarque dos aliados em 1943, o fim da guerra, os impulsos separatistas e o desejo de alguns que esperavam poder fazer a Sicília se tornar parte dos Estados Unidos, o plebiscito que sanciona o nascimento da República Italiana, as primeiras eleições regionais sicilianas (20 de abril de 1947), cuja intensa campanha eleitoral Mangione seguiu com curiosidade participativa e cujos êxitos suscitaram o seu interesse de cidadão democrático e de estudioso.

Este tempo ele transcorreu entre Agrigento e Porto Empedocle, onde conheceu Dante Bernini e Andrea Camilleri, que no livro é chamado de Andrea Bellini por razões que mais adiante conheceremos através das palavras do próprio Camilleri.

A Bernini caberá a tarefa de recordar Mangione, morto em 1998, com um artigo que evoca o momento quando se conheceram, em um pós-guerra marcado principalmente pelo encontro com os americanos e, entre este, com "os que falavam uma espécie de dialeto siciliano, arcaico inclusive nas cadências": no drama da guerra, portanto, a extraordinária - e positiva - novidade representada pela descoberta das línguas. Inclusive da língua falada por Mangione, para quem,

aquele dialeto (aprenderam com os pais no gelo de Rochester - insólito para os sicilianos) era a chave, ou melhor, talvez a alavanca usada para adentrar naquele grande mistério que eram a Sicília e a alma dos sicilianos, que lhe tinham deixado sementes, apesar de tudo. 8

O hóspede proveniente de Rochester, em toda a Sicília, e particularmente em Agrigento e Porto Empedocle, foi acolhido por um ambiente intelectual do qual Dante Bernini e Andrea Camilleri tinham saído. E foi justo este último quem deu informações sobre Bernini, remontando aos tempos de escola e do passeio pela Via della Libertà 9 ; recordando como, com alguns colegas da época da escola (entre os quais havia Gaspare Giudice, futuro biógrafo de Pirandello), tinham dado vida à publicação de um jornal escolar.

Quando Mangione realizou a sua segunda viagem para a Sicília, os antigos colegas já estavam na universidade e tinham assumido um papel de destaque no ambiente cultural e político local. Não nos deteremos nos trechos do ambiente que Mangione descreve em Reunião na Sicília, nem nas situações de que é protagonista Andrea Bellini, conhecido como Camilleri, mas para chegar finalmente no episódio tema deste trabalho, será útil acenar pelo menos a dois momentos em que Andrea e Jerre agem juntos. O primeiro é relativo a uma "representação da Ópera"10, na verdade da Ópera de bonecos que retornará nos textos camillerianos e ocupa um papel importante na vida local. O segundo, a visita à casa natal de Pirandello, chama a nossa atenção não somente pelo fato em si (a visita a um lugar considerado altamente significativo pelo jovem Andrea "que frequentou o lugar"11 e a menção das situações ligadas ao retorno das cinzas de Pirandello, propiciado por um grupo de amigos, entre os quais o próprio Camilleri que em seguida contará o episódio nos seus escritos e nas entrevistas), mas também porque oferece a oportunidade a Mangione de traçar as linhas de um retrato do escritor quando jovem, de indubitável interesse:

Pelo caminho falamos dos escritores americanos que tinha lido e gostado e depois 
falamos dele. Está para partir para Milão para trabalhar como curador em uma editora. Uma revista literária italiana muito prestigiosa - "Mercúrio" - aceitou algumas poesias suas, e ele está cheio de esperança e ambição, qualidade que vi bem pouco nos jovens sicilianos. Pergunto a ele porque quer deixar a Sicília e ele rebate adequadamente: "O que lhe levou a deixar a sua cidade natal para ir para Nova Iorque?". Intelectualmente, a Sicília é limitada demais para o seu gosto. Uma vez por mês vai a Palermo, "por necessidade", para ir a concertos e a peças de teatro, e para ler uma coletânea de escritos de Proust que um amigo tem. Segundo Andrea, é a única coletânea de Proust na Sicília. Estes passeios o ajudam a "suportar" o provincialismo de Porto Empedocle, mesmo fazendo ele gastar o dinheiro que usaria para comprar roupa12.

Traçamos assim o perfil dos dois personagens que serão protagonistas do episódio tema da nossa atenção. Antes de começar, é preciso somente dizer que ambos apreciam o fascínio da beleza na naturezalse na arte: e este pode ser o fio condutor do passeio a Monserrato que Mangione e Camilleri, de modo diverso, mas com elementos em comum, narraram.

Reunião na Sicília conta sobre um passeio a Monserrato onde havia um antigo monastério dominicano, em um lugar situado "a seis sete quilômetros de Porto Empedocle"14. O objetivo da excursão é ver "algumas pinturas artísticas dos monges" 15.

Como se fazia no bom tempo antigo, se vai a pé, obviamente, transportando um pouco cada um uma mochila pesada com garrafas de vinho, pão e queijo, pelos vales solitários e colinas "manchadas de rebanhos de ovelhas"16, cheios de reentrâncias onde não é difícil imaginar que possam se esconder bandidos. Neste cenário arcádico e também inquietante, o encontro com "alguns homens a cavalo" poderia ser fonte de preocupação, porém, o medo desaparece quando eles "cumprimentam Andrea com todo respeito"17. O conto de Mangione nos havia proposto a figura de Andrea como a de um jovem intelectual de múltiplos interesses; aqui o retrato ganha um aspecto imprevisto, que diz sobre a família à qual pertence, um núcleo sólido, ligado ao lugar e transformado em um respeito que reverbera no mais jovem.

Não menos preocupante, já no alto do monte, a recepção foi feita por "um monte de vira-latas", que depois foram entretidos por um homem a cavalo, líder da pequena vila localizada em Monserrato e avô das crianças que apareceram junto com os cães:

Montado bem reto em um cavalinho branco, com uma carabina a tiracolo e a barba preta que chegava à crina do cavalo, o velho era a imagem perfeita de um antigo patriarca18.

Antigo, mas perfeitamente atualizado sobre as coisas do tempo presente: conhecido como o americano, propõe um brinde com "o seu vinho em homenagem aos Estados Unidos" e depois, chamando o hóspede em um canto, lhe pediu "para ajudá-lo a encontrar estreptomicina para a sua filha que, dizia, estava morrendo de tuberculose" 19.

Passadas as formalidades, se passa à visita das obras de arte: "uma imagem de terracota de Nossa Senhora"20e, finalmente, os afrescos:

Três das quatro paredes da cela estavam cobertas de afrescos desbotados que representavam figuras em tamanho natural de São Calógero, Santa Rosália, São Roque, São Gerlando e São Jorge. As cores predominantes eram o vermelho e o azul. O estilo recordava muito os afrescos pintados pelo grande dominicano Fra Angelico. Sob o altar, Andrea encontrou o emblema da Florença antiga, que reforçou a nossa hipótese que os afrescos pudessem ter sido pintados por um outro monge dominicano que vivia em Firenze, onde tinha conhecido a obra de Fra Angelico.

Percebi que os murais incluíam figuras de cães muito parecidos com aqueles que tinha visto no alto da montanha. O patriarca a chamava de "semelhança de família", e dizia 
que os seus cães descendiam dos cães pintados nos murais. E para provar a sua afirmação, chamou um dos cães e apontou inegáveis similaridades entre eles. Por mais que pudesse parecer uma fantasia, a mesma família de cães que tinha vivido em Monserrato no século XV ou talvez antes, ainda existia e vivia nos mesmo lugares.

A conversa continua durante o café da manhã sobre o tema da proteção das pinturas e Andrea afirma que estaria interessado na sua tutela. Depois, aberta a segunda garrafa de vinho, o assunto muda e se passa a falar de uma moça que "tinha tido uma educação liberal na arte de amar" 22: o passeio acabou e voltaram para Porto Empedocle.

Assim Jerre Mangione conclui o que pode ser considerada uma crônica do evento vivido junto a Andrea Bellini, isto é, Andrea Camilleri, que, como já dito, contará, do seu modo, o episódio. Mas, antes de chegar nele, pode ser útil ver o que ele diz de Mangione na longa entrevista a Saverio Lodato que, recordemos, é de 2002: então acontece em uma data entre Excursão a Tíndari (2000) e Exercicios de memória (2017). escritores:

Particularmente viva - e quase cômica - é a cena do primeiro encontro entre os dois

Camilleri explica ao entrevistador as razões da mudança do nome, como cautela com o anticomunismo dos Estados Unidos:

E então Jerre, que era um grande cavalheiro - e já começavam os tempos duros da caça às bruxas - pensa: se escrevo que o meu amigo é comunista, nunca o trariam para os Estados Unidos. Então me rebatiza de "Andrea Bellini” para não arruinar a minha reputação nos States, esperando que um dia eu pudesse retribuir a sua visita24;

e depois retoma sutilmente um fato que conhecemos através das palavras de Mangione:

Com Jerre Mangione fizemos até uma boa ação. [...] No pós-guerra, como se sabe, era dificílimo encontrar penicilina25. Durante um passeio por uns campos distantes, depois de Agrigento, descobrimos uma família em que alguém estava morrendo justo por falta de penicilina. Jerre conseguiu que lhe mandassem par avion dos Estados Unidos. E conseguimos salvar aquela vida [...].

Agora que reconstruímos, pelo menos um pouco, os fatos que pertencem à vida real (sem esquecer, que fique claro, que até falando sobre uma viagem ou respondendo a uma entrevista o corte narrativo impõe um certo afastamento do que efetivamente aconteceu), podemos ler a página que parte daqueles pontos:

Era chamada de Monteserrato uma sequência de colinas altas que dividia Montelusa de Vigàta. Partia praticamente do mar e ia além por cinco ou seis quilômetros em direção aos campos da zona rural. No último cume havia uma velha e grande fazenda. Era um lugar isolado. E assim tinha ficado, apesar de que no tempo da construção desordenada de obras públicas, em uma busca desesperada por um lugar que justificasse uma estrada, uma ponte, um viaduto, uma galeria, o tivessem ligado com uma faixa de asfalto até a estrada provincial Vigàta-Montelusa. De Monteserrato tinha lhe falado há alguns anos antes Burgio, o antigo diretor da escola. Tinha lhe contado que em 1944 tinha ido fazer uma excursão a Monteserrato com um amigo americano, um jornalista com quem tinha logo se simpatizado. Tinham caminhado por horas pelos campos, depois começaram a subir, descansando de tempos em tempos. Quando avistaram a fazenda, circundada por altas muralhas, foram parados por dois cães de uma raça que nem o diretor nem o americano nunca tinham visto. Corpo de galgo, mas com cauda curtíssima e enrolada igual de porco, orelhas compridas das raça de caça, olhar feroz. Os cães os tinham literalmente imobilizado, qualquer avanço e os cães rosnavam. Depois finalmente passou a cavalo um sujeito da fazenda que os 
acompanhou. O chefe da família os levou para visitar os restos de um antigo convento. $\mathrm{E}$ ali o diretor e o americano, em uma parede úmida em péssimas condições, viram um afresco extraordinário, uma Natividade. Ainda dava para ler a data: 1410. Estavam pintados também três cães, completamente idênticos aos que os tinham parado na chegada. O diretor, muitos anos depois, depois da construção da estrada asfaltada, queria voltar lá. As ruínas do convento não existiam mais, no lugar delas havia uma imensa garagem. Até a parede com o afresco tinha sido posta abaixo. Em torno à garagem ainda havia pedaços de gesso colorido26.

Estamos no livro Excursão a Tíndari, quinto romance do qual é protagonista o comissário Montalbano2728 - a quem também, antes deste romance, foram dedicados os contos das coletâneas Um mês com Montalbano (1998) e O ano novo de Montalbano (1999)29 - e o autor preparou a série investigativa construindo em torno ao detetive paisagens naturais e humanas que o leitor conhece e, reconhecendo, encontra-se em um ambiente, por assim dizer, familiar, que lhe consente realizar sem tropeços a sua leitura. Tem familiaridade tanto com as paisagens entre mar e campo, assim como com personagens como Burgio, diretor aposentado da escola de Vigàta, figura chave para a solução de alguns mistérios; e não somente por isto.

Burgio entrou em cena em $O$ cão de terracota (1996)e o encontramos depois em Um diário de 1943 (parte da coletânea Um mês com Montalbano), em Uma mosca apanhada no ar e em $O$ ano novo com Montalbano (conto publicado na coletânea homônima)3031. Em Excursão a Tindari, elecontinua a desempenhar o papel que lhe foi designado pelo autor: pertence a uma geração anterior à de Montalbano e fornece informações em primeira mão sobre acontecimentos de um tempo em que o comissário ainda não tinha nascido; além disso, como todos os idosos que viram o crescimento das casas e a mudança das suas características, manifesta uma nostalgia pelo tempo passado que quase coincide com um tipo de moderna consciência ecológica.

Ambas características estão presentes no episódio objeto do nosso estudo, que é como que concluído em si mesmo, isolado do espaço vazio que o precede e o que o segue, conferindo a ele um tipo de autonomia no interior do romance. Montalbano chega a Monteserrato para realizar uma investigação, lembrando de um episódio narrado pelo diretor Burgio (que portanto se configura como um conto dentro do conto), do qual tinha sido protagonista, ou melhor, tinha ali o mesmo papel que Reunião em Sicília dá a Camilleri. Burgio, portanto, faz um passeio com um amigo americano, jornalista, podemos imaginar levado à Sićlia por causa dos eventos bélicos. Neste caso também, chegam próximos a uma construção e precisam parar por causa dos cachorros. Para socorrê-los chega um homem a cavalo, o dono da casa, que os leva para visitar as ruínas de um antigo convento. As paredes estão degradadas pela humidade, contudo é bem visível um afresco, datado de 1410, que representa a Natividade: estão representados três cães, idênticos àqueles que os pararam na chegada. Anos após, o diretor, tendo voltado ali, não encontrará mais o convento, porque foi demolido para se construir uma garagem em torno à qual permaneceram os fragmentos coloridos da parede com o afresco.

Transcorrido muito tempo, Camilleri, já aos noventa anos e afetado pela cegueira, reage às surpresas do destino recorrendo à memória extraordinária de que dispõe e que lhe consente reconstruir na visão interior, pincelada por pincelada, cor por cor, os quadros que amou, como também recordar fatos e pessoas da sua longa vida. Recorda e conta: nasce assim o livro Exercícios de memória (2017), que contém mais de vinte histórias: a primeira é As cinzas de Pirandello, que testemunha um longo amor, não somente pela obra, mas também pela personalidade do dramaturgo que se projeta, superando a morte com êxitos pirandellianos, até o momento da dispersão das cinzas.

O último conto se intitula $A$ Beleza Avistada e assim começa:

A separar o território da minha cidade Porto Empedocle do território da capital Agrigento há uma longa colina que se chama Monserrato32.

Um incipit que parece reivindicar, com força, os direitos da realidade em relação à criação artística, a retomada de uma história que lhe pertence, e que certa vez tinha sido contada por Mangione e uma outra tinha sido emprestada a Montalbano (ou ao diretor Burgio, que no fundo representa Camilleri). Essa deveriaser a versão autêntica, a que restabelece a verdade dos fatos. 
Mas será que é exatamente assim? Poderá o velho conta- histórias já cego economizar o dom que o distinguiu na vida, isto é, a capacidade de saber levar o conto (como dizia Leonardo Sciascia, retomando uma expressão própria do mundo camponês siciliano), que no fim das contas consiste em saber adequar os fatos às regras da comunicação, expressa tanto na literatura oral quanto na escrita? Por outro lado, falando de Van Gogh (mas o conceito talvez valha como descrição da própria poética), Camilleri observou:

Há uma frase de Van Gogh em uma carta ao irmão que trago dentro de mim por anos e anos. Diz mais ou menos assim: "Por todo o ano trabalhei debruçado na natureza e ainda hoje noto que me deixei escapar algumas estrelas grandes demais". Então, por mais que se esforce para reproduzir fielmente a natureza, Van Gogh não consegue não fazer estrelas desproporcionais. O impulso ao qual você cede consciente é mais forte do que o que você está vendo e de como deveria fazer na tela. É completamente consciente do seu erro de perspectiva, mas não sabe parar o pincel, que é a continuação do seu ser, que, quase que por vontade própria, aumenta as estrelas. Talvez o segredo da arte esteja todo ali33.

Com essa agradável dúvida (de Camilleri sobre a arte, e nossa sobre ele), podemos iniciar a leitura da lembrança que Camilleri dedica a Monserrato e à Beleza, naquele lugar avistado.

A exposição da excursão a Monserrato se articula em três momentos: o primeiro, brevíssimo, quase como um prefácio, narra o passeio de um Camilleri de catorze anos por algumas casas isoladas no campo, onde se dizia que moravam pessoas bem rudes, que não gostavam de receber visitas. Chegando perto das casas, o rapaz foi parado

por dois cães de uma raça que eu nunca tinha visto, eram elegantes como os galgos, mas tinham uma cauda fina espiralada, devia ser bem comprida, os dois cães me cercaram um pela frente e um por trás, que eu não podia dar um passo, que rosnavam e mostravam os dentes me ameaçando. 34

Em todos os três textos analisados aparecem cães com esse papel mais ou menos inquietante, mas de todo modo significativos pelas suas características, que levam (como neste caso ainda vamos ver) aos animais pintados nos afrescos. Na introdução, de qualquer modo, ainda não se fala dos afrescos: o rapaz, de fato, socorrido por um camponês que, sem nem olhá-lo nos olhos, chama os cães, voltou para casa nas carreiras.

Chegamos, então, ao primeiro ato da visita propriamente dita que Camilleri data, sem hesitar, "em outubro de 1943, depois do desembarque dos americanos"; uma modificação da cronologia que constitui um sinal: o que estamos examinando não é uma recordação, ou não é somente uma recordação. Já é uma reelaboração narrativa que arrasta os acontecimentos no tempo, antecipando-os para 1943.

É uma situação ímpar que a questão dos cães permaneça sempre igual, enquanto as datas mudam: 1947 na realidade dos fatos afirmada por Mangione e confirmada por Camilleri na citada entrevista a Saverio Lodato; antecipada para 1944 em Excursão a Tíndari, e agora retroagindo mais um ano em Reunião na Sicília. Descarta-se logo a possibilidade de uma confusão na lembrança: é fato que muitos têm dificuldade para recordar as datas. Mas não Camilleri, que por toda a sua vida teve uma louvável capacidade de se lembrar de datas, fatos, pessoas conhecidas e reconhecidas, primeiro visualmente e depois só com a audição: sem hesitação ou possibilidade de erro.

O velho e ainda corajoso conta-histórias, portanto, está fazendo com habilidade o seu ofício que, por mais que se esforce para reproduzir fielmente a natureza, ele o impede e lhe impõe que aumente as estrelas. Com tal objetivo, se serve de nada mais nada menos que do desembarque dos americanos, um dos eventos mais marcantes na história da Sić́lia moderna, inciso no sentimento da insularidade siciliana, na sensibilidade dos escritores, na visão de tantos que viveram aquilo, jovens (como Camilleri, que em 1943 tinha dezoito anos) ou nem tão jovens. Assim, a suposta recordação se insere na epopeia e Jerre Mangione não é, como de fato foi, um pesquisador que chegou na ilha com uma bolsa de estudo para desenvolver a sua pesquisa, mas "um escritor sículo-estadunidense" (em Excursão a Tíndari era um jornalista) que chegou a Porto Empedocle "com o exército americano". Embedded, se diria na Itália do novo milênio, fascinada pelos 
enviados de guerra que, com o exército em que são incorporados, dividem os perigos como também as vantagens: os tratamentos no hospital militar, no caso da Itália; o que veremos mais adiante.

Sem prejuízo dessa inicial e não secundária modificação, o conto prossegue seguindo a trilha aberta por Reunião na Sicilia: Camilleri e Mangione se tornam logo amigos e o primeiro propõe fazerem um passeio a Monserrato. Desta vez não são parados por cães (que porém são invocados), chegam até as casas isoladas, pedem água e recebem "vinho fresquíssimo" 35 ; mas há uma mulher doente, e Mangione sugere levá-la ao hospital militar. Cria-se, assim, um subconto que retoma um ponto apenas acenado em Reunião na Sicília (mas completamente ausente em Excursão a Tindari) e o desenvolve: ali havia apenas um sinal, com o pedido da estreptomicina, que, de fato, um pesquisador americano tinha alguma possibilidade de fornecer, mesmo não sendo de nenhum modo ligado ao ambiente médico. Já aqui o desenvolvimento é mais amplo e articulado, interrompe pouco a narrativa principal, para ser retomado depois que o conto da visita aos afrescos terminou.

Seguiremos o andamento narrativo e acompanharemos os dois amigos na visita que estão para fazer, e que se desenvolve no tempo em que a enferma se prepara para ir para o hospital militar.

O ambiente que visitam é um estábulo para cavalos (aqui também os cavalos) onde um dos animais, batendo-se contra uma parede, a derruba, descobrindo-se assim um afresco que reproduzia uma paisagem com dois monges e um cão parecido com aqueles encontrados. É a paisagem pintada que nos interessa principalmente:

O céu era de um azul intenso, somente no lado direito havia algumas nuvenzinhas brancas, depois se viam os campos semeados e, distantes, as silhuetas de quatro cidades, entre as quais, Agrigento: a mesma idêntica paisagem, torno a repetir, que se via de fato. Dava uma sensação de amplitude, de grandeza e, ao mesmo tempo, de serenidade36.

Este é o ponto focal da nossa reflexão: precisamos conseguir colher o profundo sentido de uma descrição em que não há nada de inventado ou de ampliado: pelo contrário, o escritor é preciso e repete: "é a mesma idêntica paisagem que se via de fato". E diz ainda: "Dava uma sensação de amplitude, de grandeza e, ao mesmo tempo, de serenidade".

Vale a pena recordar: estamos em 2017 e Camilleri reflete, como mais profundamente fará em Conversa sobre Tiresia37, permanecendo ligado àquele mundo geográfico e humano, que perfeitamente coincide com o cenário privilegiado em que é ambientada a sua obra. Olha do alto da montanha de Monserrato: vê "as silhuetas de quatro cidades, entre as quais, Agrigento" e o que vê dá a quem escreve, e comunica a quem lê, "uma sensação de amplitude, de grandeza e, ao mesmo tempo, de serenidade". Pensemos na angústia do mundo descrito por Pirandello; pensemos no que vê Chevalley, em $O$ Leopardo, quando "diante dele, sob a luz de cinzas, a paisagem estremecia, irredimível"38; pensemos em Sciascia: quantos outros escritores sicilianos falaram da sua terra descrevendo-a como geradora de uma sensação de amplitude, de grandeza, de serenidade?

Para melhorar o conceito, Camilleri dispõe de um afresco que, com toda evidência, não foi realizado por um pintor qualquer:

As pinceladas foram traçadas com mão segura. Com certeza quem tinha feito aquele afresco não era um amador nem um naïf, era claramente alguém do meio, alguém da arte, um verdadeiro pintor. Embaixo à direita não havia a assinatura, somente uma data em números romanos: MCDXX. Era difícil tirar os olhos daquele afresco, tinha o fascínio secreto próprio das obras de arte, que não conseguimos conter o entusiasmo39.

Deve-se perceber, en passant, que esta data também mudou, adicionando dez anos em relação à Excursão à Tíndari, mas o que interessa perceber é o olhar do especialista que vê e descreve uma obra de arte.

Devemos recordar que a arte foi para Camilleri como a flauta doce para Umberto Eco: não era um interesse primário, mas também não era um mero passatempo. Foi competência e paixão pela arte italiana do século XX, disse Rita Ladogana40. Vale dizer que o nosso escritor também 
mostrou tanto interesse pela pintura antiga quanto pela contemporânea, italiana e não somente; e pela fotografia: como emerge com evidência a partir de um reconhecimento dos lugares - contos, romances, entrevistas - nos quais o tema é abordado e que documentam a competente paixão de Camilleri pela arte 41 . Tudo isto é necessário saber para compreender melhor a amplitude que a descoberta do afresco tem em relação à narrativa de Excursão à Tindari, e poder avaliar melhor a conclusão, complementada em A Beleza avistada, que transcende o episódio em si para se lançar em direção a concepções de interesse mais geral.

Isto que no romance do anos 2000 era resolvido em poucas linhas ("O diretor, muitos anos depois, depois da construção da estrada asfaltada, queria voltar lá. As ruínas do convento não existiam mais, no lugar delas havia uma imensa garagem. Até a parede com o afresco tinha sido posta abaixo. Em torno à garagem ainda havia pedaços de gesso colorido"), adquire agora um maior relevo e merece toda a parte conclusiva da recordação.

Camilleri assume em primeira pessoa o papel que em Excursão a Tíndari tinha emprestadoao diretor Burgio; além disso chama para dar um suporte com esta experiência um artista, o escultor Angelo Canevari42.

A mesma decisão de realizar a visita é bem mais engendrada em relação à do diretor Burgio que precisava se afastar poucos quilômetros de Vigàta: já agora, trata-se de organizar "uma partida para a Sicília acompanhados das respectivas mulheres" 43 e de predispor o plano e os instrumentos, adquirir, "remover e transportar numa tela" 44 o afresco para levá-lo para Roma. Uma operação particularmente complexa pela qual há a necessidade de uma "base" que, em Porto Empedocle, é constituída pela "casa de campo"45. Camilleri não diz mais nada, mas o seu leitor sabe bem a importância daquela casa, cenário e protagonista de muitos episódios contados em diversas obras.

Quando o objetivo está para ser alcançado, acontece o inesperado coup de théâtre. Em Excursão a Tíndari, o convento tinha sido demolido, banalmente, para se construir uma garagem. E isto era um procedimento comum, devido à modernidade e a algumas improbidades administrativas justificadas com a expressão "porque sim" 46 : nos anos precedentes o convento tinha sido poupado, talvez porque fosse contra-mão, fora da busca de lugares onde construir estradas, pontes, viadutos "porque sim", de fato, ou, talvez tenha sido devido a uma gestão mais dedicada e atenta ao interesse privado que à utilidade pública. O convento tinha antes resistido, mas, no fim, acabou sendo demolido pela insensata ação do homem.

Em A Beleza avistada, somos transportados para uma dimensão bem mais potente e dramática: o casario foi abaixo por uma "passada" de terremoto. Estamos, portanto, em uma esfera mística de forças naturais, contra as quais o homem não pode se opor, e a solene conclusão nos projeta para uma estética visual. Tudo o que resta do afresco são pedrinhas coloridas "de um azul intenso". Só resta sair dali:

saímos dali abatidos e fomos para a casa dos meus avós, eu de tanto em tanto colocava a mão no bolso e tocava a pedrinha colorida, que era o sinal palpável de que uma vez tinha me sido concedida a graça de avistar a Beleza47.

São as palavras conclusivas da recordação de Camilleri e de todo o livro Exercícios de memória; mas podem ser consideradas como o legado que o Mestre quis oferecer a cada um de nós.

A Beleza (da natureza, da terra natal, dos quadros, das mulheres) é um bem cuja posse é negada aos seres humanos que podem somente avistá-la, e se lhes for concedida essa graça.

Vale fazer um adendo que nos transporta do plano metafísico ao terrestre das responsabilidades humanas e permite compreender um outro aspecto dos entendimentos gerais sobre os quais Camilleri construiu a sua obra. Viver "ao bel prazer" pode ser, no momento, agradável (e para alguns vantajoso), mas tem um custo que mais cedo ou mais tarde deve ser pago e que principalmente consiste na perda da noção de pertença, no apagamento daquela Beleza em que originariamente vivíamos imersos. Quantos tiveram a sorte de nascer em Agrigento? E, levando em consideração um plano mais amplo, na Sicília? Nas margens do mar Mediterrâneo, como em todas as parte do mundo em que aquela Beleza tinha sido confiada à guarda dos homens?

Recompondo assim os fragmentos, pedrinha por pedrinha, do grande afresco que Camilleri pintou, mais uma vez descobrimos que toda a sua obra pode ser classificada recorrendo às categorias histórico e civil, inicialmente reservadas somente a um grupo de romances 48 .

\section{REFERÊNCIAS}


BERNINI, Dante, Jerre Mangione ad Agrigento. Un ricordo. Disponível em: . Acesso em: 10 fev. 2020.

BORRELli, ANTONIO, San Gerlando di Agrigento vescovo. Disponível em: . Acesso em: 13 fev. 2020.

Camilleri Fans Club. Disponível em: . Acesso em: 14 fev. 2020.

CAMILLERI, A. La gita a Tindari. Palermo: Sellerio, 2000.

. Excursão a Tíndari. Trad. Joana Angélica d'Ávila Melo. São Paulo: Record. 2002.

. Il cielo rubato. Dossier Renoir. Ginevra-Milano: Skira, 2009.

. Una voce di notte. Palermo: Sellerio, 2012.

. Un'amicizia. Angelo Canevari. Ginevra-Milano: Skira, 2012.

Segnali di fumo. Novara: Utet-De Agostini, 2014.

. Il quadro delle meraviglie. Scritti per teatro, radio, musica, cinema. Palermo: Sellerio, 2015.

. La Bellezza intravista, in: Esercizi di memoria, Milano, Rizzoli, 2017.

MARCI, GIUSEPPE, RUGGERINI, MARIA ELENA, "L'arte nelle opere di Andrea Camilleri”, in D. CAOCCI, G. MARCI, M. E. RUGGERINI (a cura di), Quaderni camilleriani 12. Parole, musica (e immagini). Cagliari, Grafiche Ghiani, 2020, pp. 15-35.

LADOGANA, RITA, "L'arte italiana del Novecento nel Montalbano di Andrea Camilleri”, in Medea. vol. II, n. 1, giugno 2016.

LODATO, S. La linea della palma. Milano: Rizzoli, 2002.

MANGIONE, J. Riunione in Sicilia. Palermo: Sellerio, 1992.

MARTINI, ALESSANDRO, "Le ciliegie della memoria: quando Montalbano si misura con la storia", in C. FAVERZANI, D. LANFRANCA (a cura di), Quaderni camilleriani 2. La storia, le storie. Camilleri, la mafia e la questione siciliana. Cagliari: Grafiche Ghiani, 2016, pp. 47-52.

PREZZOLINI, GIUSEPPE, "Gli emigrati ritornano in Italia e non ci si ritrovano più", in MANGIONE, J. Riunione in Sicilia. Palermo: Sellerio, 1999, pp. 297-303.

ROSSO, LORENZO. Conversazioni con Andrea Camilleri. Caffè Vigàta. Reggio Emilia: Aliberti editore, 2007.

SUTHERLAND, J. (a cura di). Atlante dei paesaggi letterari. Milano: Rizzoli, 2019.

TOMASI DI LAMPEDUSA, G. Il Gattopardo. Milano: Mondadori, 2011.

. O Leopardo. Trad. Maurício Santana Dias. São Paulo: Companhia das Letras, 2017, p. 65.

\section{NOTAS}

1 N. do A.: Esse trabalho deveria ter sido apresentado no Seminário sobre Andrea Camilleri na Sicília em abril de 2020, cancelado pelas questões sanitárias do momento. Contudo, tais questões não podem nos impedir de cumprir o nosso trabalho e nem de deixá-lo público, como testemunho de resistência e de esperança: que logo todos possamos voltar às nossas rotinas e realizar encontros presenciais, onde há partilha de cultura e de afeto.

2 N. do A.: SUTHERLAND, J. Atlante dei paesaggi letterari. Milano: Rizzoli, 2019, p. 10.

3 N. do T.: La gita a Tindari(2000), traduzido no Brasil, por Joana Angélica d'Ávila Melo, publicado pela Record em 2002.

4 N. do T.: Sem tradução publicada no Brasil.

5 N. do A.: PREZZOLINI, G. "Gli emigrati ritornano in Italia e non ci si ritrovano più", in J. MANGIONE, Riunione in Sicilia. Palermo: Sellerio, 1992, p. 299. 
N. do T.: Sem tradução publicada no Brasil.

7 N. do A.: MANGIONE, 1992, p. 12.

8 N. do A.: BERNINI, D. Jerre Mangione ad Agrigento. Un ricordo. Disponível em: . Acesso em: 10 fev. 2020.

9 N. do A.: Cfr. ROSSO, L. Conversazioni con Andrea Camilleri. Caffè Vigàta. Reggio Emilia: Aliberti editore, 2007, pp. 31 e 37.

10 N. do A.: MANGIONE, op. cit., p. 179.

11 N. do A.: Ibid., p. 184.

12 N. do A.: Ibid., pp. 182-183.

13 N. do A.: Ibid., pp. 211-212.

14 N. do A.: Ibid., p. 198.

15 N. do A.: MANGIONE, loc. cit.

16 N. do A.: Ibid., p. 199.

17 N. do A.: MANGIONE, loc. cit.

18 N. do A.: MANGIONE, loc. cit.

19 N. do A.: MANGIONE, loc. cit.

20 N. do A.: Ibid, p. 200.

21 N. do A.: MANGIONE, pp. 200-201.

22 N. do A.: Ibid., p.201.

23 N. do A.: LODATO, S. La linea della palma. Milano: Rizzoli, 2002. p. 182.

24 N. do A.: Ibid., pp. 182-183.

25 N. do A.: Perceba-se a mudança do remédio: Mangione fala de estreptomicina, Camilleri de penicilina.

26 N. do A.: CAMILLERI, A. Excursão a Tindari. Palermo: Sellerio, 2000, pp. 236-237.

27 N. do A.: Os anteriores são La forma dell'acqua (1994), Il cane di terracotta(1996), Il ladro di merendine(1996), La voce del violino (1997).

28 N. do T.: Foram traduzidos no Brasil por Joana Angélica d'Ávila Melo e publicados pela Record, respectivamente, com os seguintes títulos: A forma da água (1999), O cão de terracota (2000), O ladrão de merendas (2000) e A voz do violino (2001).

29 N. do T.: Traduzidos no Brasil, respectivamente, como Um mês com Montalbano (2002) e O ano novo de Montalbano (2009), por Joana Angélica d'Ávila Melo, publicados pela Record.

30 N. do A.: O diretor Burgio retornará em L'odore della notte (2001), Le ali della sfinge(2006), L'età del dubbio(2008) e Una voce di notte (2012).

31 N. do T.: L'odore della notte(2001) foi traduzido no Brasil como O cheiro da noite(2003), por Joana Angélica d'Ávila Melo, pela Record. Le ali della sfinge(2006) [As asas da esfinge] e L'età del dubbio(2008) [A idade da dúvida] não foram traduzidos no Brasil. Una voce di notte(2012) foi traduzido no Brasil como Uma voz na noite (2019), por Ivone Benedetti, também pela Record.

32 N. do A.: CAMILlERI, A. La Bellezza intravista, in ID., Esercizi di memoria. Milano: Rizzoli, 2017 , p. 231. Aqui o topônimo, transformado em Excursão a Tíndari, retoma a sua grafia normal.

33 N. do A.: CAMILLERI, A. Segnali di fumo. Novara: Utet-De Agostini, 2014, p. 146.

34 N. do A.: CAMILLERI, 2017, p. 232.

35 N. do A.: Ibid., p. 233.

36 N. do A.: Ibid., p. 234.

37 N. do T.: CAMILlERI, A. Conversazione su Tiresia. Palermo: Sellerio, 2018. Sem tradução no Brasil. 
38 N. do A.: TOMASI DI LAMPEDUSA, G. O Leopardo. Trad. Maurício Santana Dias. São Paulo: Companhia das Letras, 2017, p. 65.

39 N. do A.: CAMILLERI, 2017, p. 234.

40 N. do A.: R. LADOGANA, “L’arte italiana del Novecento nel Montalbano di Andrea Camilleri”, in: Medea. vol. II, n. 1, junho 2016.

41 N. do A.: Cfr. G. MARCI, M. E. RUGGERINI, “L'arte nelle opere di Andrea Camilleri”, in D. CAOCCI, G. MARCI, M. E. RUGGERINI (a cura di), Quaderni camilleriani 12. Parole, musica (e immagini). Cagliari: Grafiche Ghiani, 2020, pp. 15-35.

42 N. do A.: Para a presença de Angelo Canevari na obra camilleriana, remete-se ao artigo já mencionado, de M. E. Ruggerini, Marci e Caocci; aqui é suficiente citar o livro CAMILLERI, A. Un'amicizia. Angelo Canevari. Ginevra-Milano: Skira, 2012.

43 N. do A.: CAMILLERI, 2017, p. 236.

44 N. do A.: Ibid.

45 N. do A.: Ibid.

46 N. do A.: CAMILLERI, 2000, passim.

47 N. do A.: Id., 2017, p. 237.

48 N. do A.: Desejo agradecer a Simona Demontis pelo precioso suporte bibliográfico. 